Mark C. Norris MD, Michele R. Kirkland MD, Marc C. Torjman MEd, Michael E. Goldberg MD

\title{
Denitrogenation in pregnancy
}

\begin{abstract}
This study measured nitrogen washout in ten pregnant and nine non-pregnant women to understand better how pregnancy effects denitrogenation. Nitrogen concentration was monitored continuously while the women breathed 100 per cent $O_{2}$ for three minutes and took four deep breaths of 100 per cent $\mathrm{O}_{2}$ using a circle anaesthesia system and $8 \mathrm{~L} \cdot \mathrm{min}^{-1}$ fresh gas flow. Parturients achieved 95 per cent denitrogenation significantly $(P<0.0005)$ faster than non-pregnant women $(54.5 \pm 17.8$ vs $110.8 \pm 35.7 \mathrm{sec})$. In parturients, denitrogenation for three minutes lowered expired $N_{2}$ concentration to $1.0 \pm 0.2$ per cent while four deep breaths lowered it to $5.1 \pm 1.7$ per cent $(P<$ $0.0001)$. This difference, while statistically significant, is predicted to supply only $10-15$ sec of extra protection against hypoxaemia, and thus is probably not clinically significant. The authors conclude that either two minutes of tidal breathing or four deep breaths of 100 per cent $\mathrm{O}_{2}$ provide adequate denitrogenation and similar protection against apnoeic hypoxaemia in normal parturients.
\end{abstract}

Safe practice dictates that adequate pre-oxygenation precedes rapid sequence induction of anaesthesia in the parturient. Three minutes of tidal breathing of 100 per cent $\mathrm{O}_{2}$ or four deep breaths of 100 per cent $\mathrm{O}_{2}$ within 30 seconds provide similar increases in $\mathrm{PaO}_{2}$ during induction of anaesthesia in pregnant women. ${ }^{1}$ Recently, studies in non-pregnant patients have shown that pre-oxygenation for three minutes provides better protection against oxygen desaturation ${ }^{2}$ and significantly more complete nitrogen washout than four deep breaths of 100 per cent $\mathrm{O}_{2}$. With non-pregnant patients, significant amounts of nitrogen may accumulate within the circle anaesthesia system during the four deep breath technique and dilute the inspired oxygen concentration and impair denitrogenation. Parturients, with decreased functional residual

\section{Key words}

ANAESTHESIA: obstetrical; GASES, NONANAESTHETIC: nitrogen; INDUCTION: anaesthesia; PREGNANCY: ventilation; VENTILATION: denitrogenation.

From the Department of Anesthesiology, Thomas Jefferson University, Philadelphia, PA 19107.

Address correspondence to: Dr. M.C. Norris. capacity (FRC) and increased minute ventilation ${ }^{3}$ denitrogenate more rapidly than non-pregnant women. ${ }^{4,5}$ Because of their smaller lung nitrogen stores, less nitrogen may accumulate in the breathing system when a parturient uses the four deep breath technique, improving its efficacy.

This study was designed to understand better how pregnancy effects denitrogenation with both breathing techniques.

\section{Methods}

After securing institutional review board approval, written informed consent was obtained from ten healthy parturients and nine healthy non-pregnant women. The non-pregnant volunteers rested supine on a stretcher while the parturients lay on an examining table with uterine displacement maintained by a blanket wedged under the left hip. The women breathed 100 per cent $\mathrm{O}_{2}$ at a fresh gas flow of $8 \mathrm{~L} \cdot \mathrm{min}^{-1}$ through a clear plastic face mask. Oxygen was supplied via a circle anaesthetic system and an Ohio 30/70 anaesthetic machine with an Ohio model $21 \mathrm{DC} \mathrm{CO}_{2}$ absorber.

A Nitralyzer $505^{\star}$ gas meter (Med Science, St. Louis, $\mathrm{MO}$ ) and vacuum pump continuously measured nitrogen concentration. Interfacing the gas meter with a strip chart recorder provided continuous tracings of nitrogen concentrations. The nitrogen analyzer sampled inspired and expired gas through a needle valve mounted near the mouth at the elbow of the breathing circuit. The valve was inserted through a drilled $2 \mathrm{~mm}$ orifice, which was sealed and free of leaks. The nitrogen analyzer was calibrated before each test using 0,30 , and 79 per cent nitrogen.

Once the nitrogen analyzer was calibrated, the subjects participated in two denitrogenation trials in random order. They breathed 100 per cent $\mathrm{O}_{2}$ for three minutes and took four deep breaths of 100 per cent $\mathrm{O}_{2}$ within 30 seconds. For the four deep breath trial, the women were instructed: "Take a deep breath, all the way in, and blow it all the way out" four times. To assure a tight, leak-free mask fit throughout both trials, an investigator applied the mask gently but firmly to the participant's face. The subjects breathed room air for at least $\mathbf{1 5}$ minutes between trials.

At the conclusion of the study, the nitrogen tracings were evaluated to determine the final expired nitrogen concentration with each technique. In the three-minute trial, the time required to achieve an expired nitrogen concentra- 


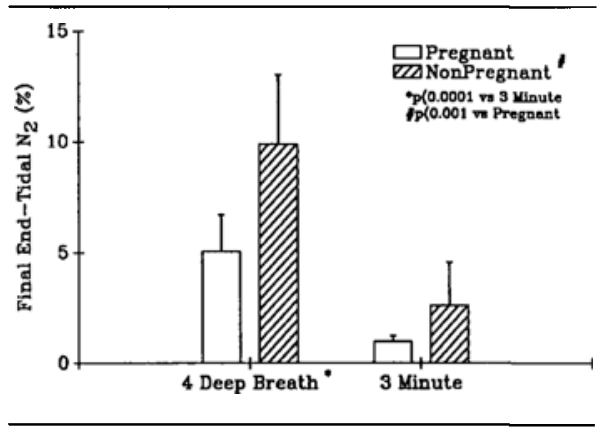

FIGURE Final end-tidal nitrogen concentration (per cent) following three minutes of tidal breathing or four deep breaths of 100 per cent $\mathrm{O}_{2}$ in ten healthy parturients and nine healthy non-pregnant females.

tion of five per cent was also measured. Two-way analysis of variance and unpaired Student's $t$ test were used to analyze the data which are presented as means \pm SD.

\section{Results}

The parturients were $23.3 \pm 4.7$ years old, $162.8 \pm 9.4$ $\mathrm{cm}$ tall and weighed $69.4 \pm 11.8 \mathrm{~kg}$. They ranged from 18 to 40 weeks gestation and had single, appropriately sized fetuses. Three of the ten smoked cigarettes. The nonpregnant volunteers were $29.1 \pm 4.3$ years old, $163.0 \pm$ $5.6 \mathrm{cms}$ tall and weighed $58.1 \pm 7.3 \mathrm{~kg}$. None smoked cigarettes nor had any history of pulmonary disease.

The figure shows the final expired nitrogen concentrations obtained with the two techniques. The non-pregnant women required $110.8 \pm 35.7 \mathrm{sec}$ to reach five per cent expired $\mathrm{N}_{2}$ while the parturients required only $54.5 \pm$ $17.8 \sec (P<0.0005)$.

\section{Discussion}

Pregnancy produces significant changes in the respiratory system, some of which alter the rate and degree of denitrogenation. The FRC decreases by $20-30$ per cent at term. ${ }^{3}$ This decrease begins in the second trimester and becomes more marked after 28 weeks' gestation. As FRC decreases, the amount of nitrogen stored in the lungs decreases and washout occurs more quickly. Similarly, minute ventilation increases throughout gestation. By the second trimester, minute ventilation rises to 30 per cent above non-pregnant levels and at term, resting minute ventilation is elevated by 50 per cent above normal. ${ }^{3}$ As minute ventilation, and consequently alveolar ventilation increases, the rate of nitrogen washout should also increase.
A recent study by Byrne et al. confirms these predictions. Using a Magill breathing system, they found a progressive decrease in the time required to achieve two per cent end-tidal nitrogen concentration from 130 seconds in non-pregnant women to 104 seconds in second trimester parturients to 80 seconds in third trimester women. ${ }^{4}$ In a similar study, also using the Magill apparatus, Russell $e t$ al. demonstrated more rapid pre-oxygenation in parturients ( 90 seconds) compared with non-pregnant women (124 seconds). ${ }^{5}$ Our study, using a circle breathing system, confirms these results and we concur with the recommendations of Byrne et al. and Russell et al. that parturients require only two minutes of tidal breathing of 100 per cent $\mathrm{O}_{2}$ to achieve adequate denitrogenation. ${ }^{4,5}$

Gold et al. ${ }^{6}$ first suggested that the four deep breath technique may provide pre-oxygenation similar to that achieved by the traditional method. In non-pregnant patients, they demonstrated that four deep breaths of 100 per cent $\mathrm{O}_{2}$ within 30 seconds provided the same increase in $\mathrm{PaO}_{2}$ and blood oxygen content as did five minutes of tidal breathing of 100 per cent $\mathrm{O}_{2}$. A subsequent study, of parturients undergoing rapid sequence induction of anaesthesia for caesarean section, found that both techniques provided similar changes in $\mathrm{PaO}_{2}$ during preoxygenation and after intubation. ${ }^{1}$ However, others have expressed concern that even though these two techniques provide similar increases in $\mathrm{PaO}_{2}$, the four deep breath technique may provide less complete nitrogen washout and less protection against hypoxaemia during apnoea. Gambee $e t$ al. measured oxygen saturation following pre-oxygenation, induction of anaesthesia and apnoea and found that $\mathrm{O}_{2}$ saturation decreases to 90 per cent more rapidly following four deep breaths $(6.8$ minutes $)$ than after three minutes of tidal breathing of 100 per cent $\mathrm{O}_{2}$ ( 8.9 minutes). ${ }^{2}$ Nitrogen accumulates in the circle anaesthesia system during the four deep breath technique, inhibiting lung nitrogen washout. However, the smaller the subject's predicted FRC, the more complete the denitrogenation achieved with the four breath technique. Thus, one would predict that parturients, with their smaller FRCs, may achieve more complete denitrogenation than non-pregnant women when performing the four deep breath technique. The results in this study confirm this prediction. Parturients achieve a significantly greater degree of denitrogenation with the four deep breath technique than do non-pregnant women. Contrary to our results with the circle anaesthetic system, Russell et al. found that rebreathing and air leaks significantly impaired pre-oxygenation when parturients perform the four deep breath technique with a Magill breathing system. ${ }^{5}$

Even though the four deep breath technique provides significantly better denitrogenation in parturients compared with non-pregnant women, it still does not provide 
the same extent of denitrogenation as three minutes of tidal breathing. However, the difference between these two techniques results in only a $56 \mathrm{ml}$ increase in lung $\mathrm{O}_{2}$ stores providing only an extra 10-15 seconds protection against hypoxaemia in parturients. (Assuming FRC at term to be $1.41^{3}, 95$ per cent oxygenation and 99 per cent oxygenation would represent $1330 \mathrm{ml}$ and $1386 \mathrm{ml}$ of stored $\mathrm{O}_{2}$, respectively. At term, a parturient consumes $300 \mathrm{ml} \cdot \mathrm{min}^{-1}$ of $\mathrm{O}_{2}{ }^{7}$ and $56 \mathrm{ml}$ of $\mathrm{O}_{2}$ would supply approximately 12 seconds of $\mathrm{O}_{2}$ demand.)

In summary, this study, using a circle breathing system, confirms the findings of Byrne $e t a l$. and Russell et al. who used a Magill system, ${ }^{4,5}$ and demonstrates that parturients achieve adequate denitrogenation after only two minutes of tidal breathing. In addition, the four deep breath technique using $8 \mathrm{~L} \cdot \mathrm{min}^{-1}$ fresh gas flows also provides adequate denitrogenation in these women. The more rapid denitrogenation in parturients probably occurs because of pregnancy-induced increases in minute ventilation and decreases in FRC.

\section{References}

1 Norris MC, Dewan DM. Preoxygenation for cesarean section: a comparison of two techniques. Anesthesiology 1985; 62: 827-9.

2 Gambee AM, Hertzka RE, Fisher DM. Preoxygenation techniques: comparison of three minutes and four breaths. Anesth Analg 1987; 66: 468-70.

3 Cugell DW, Frank NR, Gaensler EA, Badger TL. Pulmonary function in pregnancy. I. Serial observations in normal women. Am Rev Tuberc 1953; 67: 568-97.

4 Byrne F, Oruro-Dominah A, Kipling R. The effect of pregnancy on pulmonary nitrogen washout. Anaesthesia 1987; 42: 148-50.

5 Russell GN, Smith CL, Snowdon SL, Bryson THL. Pre-oxygenation and the parturient patient. Anaesthesia 1987; 42: 346-51.

6 Gold MI, Duarte I, Muravchick S. Arterial oxygenation in the conscious patient after 5 minutes and after 30 seconds of oxygen breathing. Anesth Analg 1981; 60: 313-5.

7 Pernoll MC, Metcalfe J, Schlenker TL, Welch JE, Matsumoto $J A$. Oxygen consumption at rest and during exercise in pregnancy. Respir Physiol 1975; 25: 285-93.

\section{Résumé}

Pour mieux comprendre comment la grossesse influence l'élimination de l'azote, nous l'avons mesuré chez dix parturientes et neuf femmes-contrôles. Nous mesurions constamment l'azote des gaz expirés alors que les sujets respiraient de l'oxygène pur pendant trois minutes ou en prenaient quatre grandes inspirations dans un système respiratoire semi-fermé avec un débit de gaz frais de $8 \mathrm{~L} \cdot \mathrm{min}^{-1}$. L'élimination de 95 pour cent de l'azote était plus rapide chez les parturientes $(54,5$ $\pm 17,8$ vs $110,8 \pm 35,7$ sec., $P \leq 0.0005)$ et chez elles, trois minutes a respirer de l'oxygene abaissaient l'azote des gaz expirés a 1,0 0,2 pour cent alors qu'après quatre grandes inspirations, il en restait encore $5.1 \pm 1.7$ pour cent $(P \leq$ 0.0001 ). Cette dernière différence n'équivaut probablement qu'a 10 ou 15 secondes de protection contre l' hypoxémie. Donc, l'oxygène pur pendant deux minutes en respiration normale ou lors de quatre inspirations profondes suffit à laver l'azote des poumons et offre aux parturientes normales le même degré de protection contre l' hypoxémie apnéique. 